\title{
Quantum Chemical Investigations on the Structure, Bonding Orbitals, Frontier Molecular Orbitals and Reactivity Properties of Diphenylguanidine - Vulcanizing Accelerator
}

\author{
V. K. VIJAYAN ${ }^{1}$, E. PURUSHOTHAMAN ${ }^{1}$, V. ARJUNAN ${ }^{2,3 *}$ and S. MOHAN ${ }^{4}$ \\ ${ }^{1}$ Department of Chemistry, University of Calicut, Calicut-673635, Kerala, India \\ ${ }^{2}$ Department of Chemistry, Kanchi Mamunivar Centre for Post-Graduate Studies, \\ Puducherry 605 008, India \\ ${ }^{3}$ Rajiv Gandhi Arts and Science College, Thavalakuppam, Puducherry 605 007, India \\ ${ }^{4}$ Department of Physics, S.A. Engineering College, Thiruverkadu, Chennai 600077, India \\ varjunftir@yahoo.com
}

Received 14 December 2018 / Accepted 11 January 2019

\begin{abstract}
The molecular structure and reactivity parameters of diphenylguanidine (DPG) were simulated with quantum chemical calculations by using the standard $6-31 \mathrm{G}^{* *}, 6-311++\mathrm{G}^{* *}$ and $\mathrm{cc}-$ pVDZ basis sets. The bond distance of N1-C2 and N3-C2 are $1.39 \AA$ and $1.42 \AA$, respectively. The $\mathrm{N} 1-\mathrm{C} 2$ bond posses much more double bond character than the $\mathrm{N} 3-\mathrm{C} 2$ with the longer $\mathrm{C}-\mathrm{N}$ bond length, though both have partial double-bond character. The molecule exists in the more stable imino form. The $\mathrm{C}-\mathrm{N}$ bond which connects the aromatic ring has a length of 1.28-1.30 $\mathrm{A}$, close to that of a typical $\mathrm{C}=\mathrm{N}$ double bond (ca. $1.28 \AA$ ), and is shorter than the other two $\mathrm{C}-\mathrm{N}$ bonds of the guanidine. The planarity of the tabiliza group is confirmed from the determined bond angles and torsion angles. The N1-C2-N3 bond angle $\left(109.5^{\circ}\right)$ is always smaller than the other two angles (N1-C2-N4 $\left(123.2^{\circ}\right)$ and N3-C2-N4 $\left(127.2^{\circ}\right)$ ). The MEP of the molecule spread in the range $+1.224 \mathrm{e} \times 10^{-2}$ to $-1.224 \mathrm{e} \times 10^{-2}$. The range of total electron density of DPG is $+5.545 \mathrm{e} \times 10^{-2}$ to $-5.545 \mathrm{e} \times 10^{-2}$. The bonding orbital for $\mathrm{C} 2-\mathrm{N} 3$ has $38.07 \% \mathrm{C} 2$ character in a $\mathrm{sp}^{2.24}$ hybrid and has $61.93 \% \mathrm{~N} 3$ character in a $\mathrm{sp}^{1.94}$ hybrid orbital. This clearly reveals the partial double bond character of N1-C2 and C2-N3 bonds. The bond pair donor orbital, $\pi_{\mathrm{CC}} \rightarrow \pi^{*}{ }_{\mathrm{CC}}$ interaction between the phenyl ring carbon atoms are more tabilizat and the tabilization energy of these interactions lie in the range $16.97-22.78 \mathrm{kcal} \mathrm{mol}^{-1}$. The large total dipole moment of DPG (3.208 D) shows that the polar nature of the molecule. The atoms C2, $\mathrm{C} 13, \mathrm{C} 22$ and $\mathrm{C} 24$ are most prone to nucleophilic attack while the electrophilic attack is more on $\mathrm{C} 2$, $\mathrm{C} 19$ and $\mathrm{C} 12$ atoms. The sites $\mathrm{C} 2, \mathrm{C} 12, \mathrm{C} 19, \mathrm{C} 22$ and $\mathrm{C} 24$ are more susceptible to free radical attack. Fukui dual reactivity descriptor $\left(\Delta \mathrm{f}_{\mathrm{k}}\right)$, the dual local softness $\left(\Delta \mathrm{s}_{\mathrm{k}}\right)$ and the multiphilicity descriptors $\left(\Delta \omega_{\mathrm{k}}\right)$ indicate that the atoms $\mathrm{C} 2, \mathrm{C} 9, \mathrm{C} 21$ and $\mathrm{C} 22$ are more favorable for nucleophilic attack. The atoms $\mathrm{N} 1, \mathrm{~N} 3, \mathrm{C} 8, \mathrm{C} 19$ and $\mathrm{C} 23$ are more favorable for electrophilic attack.
\end{abstract}

Keywords: Diphenylguanidine, DFT, NBO, Reactivity descriptors 


\section{Introduction}

The organic compounds containing sulphur and nitrogen, especially mercaptobenzothiazoles and phenyl derivatives of guanidine are used as vulcanizing accelerators. During vulcanization the accelerators apparently converts the sulphur into an active sulphurating species that reacts rapidly with rubber than does sulphur itself ${ }^{1-3}$. The sulphurating species that donate sulphur to form of cross-links in the elastomer. The more sulphur cross-link bonds formed during that cross-linking formation changes the mobility or the flexibility of the segments.

Diphenylguanidine (DPG) is used as secondary accelerator with thiazoles and sulphenamides in natural and synthetic rubber. The storage stability of DPG is better than that of thiuram and dithiocarbamates. DPG can be used in latex as secondary gelling agent (foam stabilizer) in the silico-flouride foam process. It acts as compatibilizer with silica ${ }^{4,5}$. It is used as a primary standard for standardizations of acetous and aqueous solutions ${ }^{6}$. Metal detection is also projected to fuel market demand for $\mathrm{DPG}^{7}$.

The rubber products obtained by DPG acceleration are used as adhesives, condoms and diaphragms, disinfectants, repellents, fungicides, and insecticides used in agriculture, gloves (household, work, or hospital), heavy rubber products used in industry, leather shoes (insoles, adhesives, linings), medical devices, renal dialysis equipment, rubber in elasticised undergarments and clothing, rubber pillows and sheets, rubber shoes (sneakers, tennis shoes, etc.), soaps and shampoos, sponge makeup applicators and rubber eyelash curriers, swim wear, tires and toys ${ }^{8-10}$. In the fields of materials chemistry and medicinal Chemistry DPG have attracted much more attention ${ }^{11}$. The DPG accelerated sulphuration involves free radical mechanism but it becomes polar when $\mathrm{ZnO}$ and stearic acid are present ${ }^{12}$.

The systematic analysis of structure stability, charge density distribution, topological properties, electrostatic potential, natural bonding orbitals, frontier molecular orbitals and the reactivity properties of DPG have been carried out in the present investigation using DFT methods to give more insights to the understanding of the charge transfer property and reactivity of DPG and to the influence of the functionalised moiety on the vulcanising properties.

\section{Experimental}

The structure parameters and properties of DPG are determined by quantum chemical calculations with Gaussian- $09^{13}$ program ${ }^{14}$. The density functional theory (DFT) ${ }^{15}$ with three parameter hybrid functional (B3) ${ }^{16,17}$ for the exchange part and the Lee-Yang-Parr (LYP) correlation functiona ${ }^{18}$ have been utilised with $6-31 G^{* *}, 6-311++G^{* *}$ and cc-pVDZ basis sets. Isoelectronic molecular electrostatic potential (MEP) and electron density ${ }^{19}$ are calculated. The shape of MEP surface and frontier molecular orbitals are developed with GaussView 5.0.8 visualisation program ${ }^{20}$.

Various kinds of $i$ (donor) $\rightarrow j$ (acceptor) delocalisation and their stabilisation energy $\mathrm{E}^{(2)}$ associated with it are estimated from the second-order perturbation approach ${ }^{21-24}$. The reactivity and selectivity descriptors namely chemical hardness, chemical potential, softness, electrophilicity, nucleophilicity and the appropriate local reactivity descriptors are determined by using different kind of atomic charges (Mullikan charges, natural atomic charges, electrostatic potential derived charges, Hirshfeld charges, Chelpg charges) of the neutral, cationic and anionic species of DPG molecule.

The site-selectivity of DPG are determined by Fukui functions ${ }^{25,26}$. The vertical ionization potential (I), electron affinity (A) and the electron populations are determined by 
B3LYP/6-311++G** method. The energy of neutral N-electron species is determined by restricted B3LYP method while the energies of the $\mathrm{N}-1$ and $\mathrm{N}+1$ ionic species are estimated by open shell restricted B3LYP method. The local reactivity descriptors of the individual atoms of the molecule $s_{k}^{a}=f_{k}^{a} S, \omega_{k}^{a}=\omega f_{k}^{a}$ and $f_{k}^{a}$ where, a $=+-$ and 0 represents local philicity quantities describing nucleophilic, electrophilic and free radical attack, respectively. The static dipole moment $(\mu)$, the mean polarizability $\left(\alpha_{0}\right)$, the anisotropy of the polarizability $(\Delta \alpha)$ and the mean hyperpolarizability $\left(\beta_{0}\right)$ using $x, y$ and $z$ components are determined.

\section{Results and Discussion}

\section{Structural properties}

The guanidines with mono- or di- substitution exist in an imino and amino forms, as illustrated in Figure 1. The imino form is found to be more favoured structure by spectroscopic studies. The molecular structure and physicochemical properties have been influenced by the $\mathrm{C}-\mathrm{N}$ partial double-bond character ${ }^{27}$.

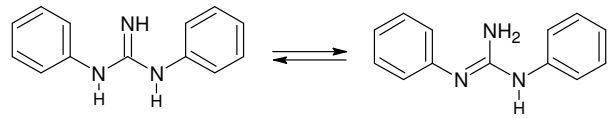

Figure 1. The tautomeric structures of diphenylguanidine

The ptimized geometry and the total electron density mapped electrostatic potential surface DPG are shown in Figures 2(a) and (b). The ptimized structural parameters namely bond length, bond angle and the dihedral angle for the stable geometry of DPG molecule determined by B3LYP methods are given in Table 1 .

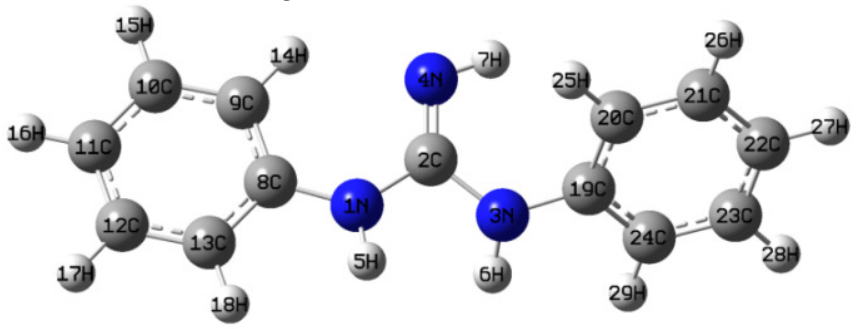

(a)

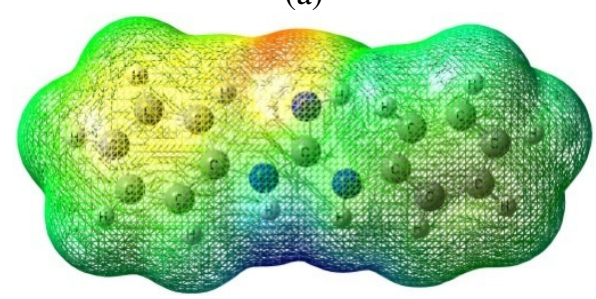

(b)

Figure 2(a). Optimised geometry and (b) Total electron density mapped electrostatic potential surface of diphenylguanidine

The energy of the different conformers of DPG using density functional theory shows that syn-syn conformer is energetically favoured ${ }^{28}$. The ptimized geometry of DPG at B3LYP/6-311++G** level is shown in Figure 2(a) and the calculated structural parameters are found to correlate well with the experimental DPG crystal geometry ${ }^{29}$. The XRD data favours 
more planarity for the guanidine moiety and the variation of XRD data from the computed values can be attributed to the calculations carried out for the gaseous state DPG. But the two phenyl rings in DPG molecule lie in different plane due to the distortions with the planar structure of guanidine moiety. Here, the $\mathrm{sp}^{2}$ hybridized central carbon atom provides more planar structure for the guanidine moiety and the ring twisting originates from the possible repulsion between the $p$-orbitals belonging to phenyl ring and delocalised guanidine moiety.

The bond distance of N1-C2 and N3-C2 are $1.39 \AA$ and $1.42 \AA$, respectively. Thus, the $\mathrm{N} 1-\mathrm{C} 2$ bonds always possess much more double-bond character than the $\mathrm{C} 2-\mathrm{N} 3$ with the longer $\mathrm{C}-\mathrm{N}$ bond length, though both have partial double-bond character. The molecule exists in the imino form in which the phenyl-bearing $\mathrm{C} 2-\mathrm{N} 4$ bond has a length of 1.28-1.30 $\AA$, close to that of a typical $\mathrm{C}=\mathrm{N}$ double bond (ca. $1.28 \AA$ ), and is shorter than the other two C-N bonds of the guanidine group (Table 1). The planarity of the guanidino group is determined from the bond angles and torsion angles. The N1-C2-N3 bond angle $\left(109.5^{\circ}\right)$ is smaller than other $(\mathrm{N} 1-$ $\mathrm{C} 2-\mathrm{N} 4\left(123.2^{\circ}\right)$ and $\mathrm{N} 3-\mathrm{C} 2-\mathrm{N} 4\left(127.2^{\circ}\right)$ ) angles. Both aromatic rings are twisted from the plane of guanidino group. The phenyl ring attached with the N1 is less twisted and more planar with the guanidine moiety while another phenyl ring connected with the nitrogen atom N3 is more twisted and nearly perpendicular to the guanidino group. It is confirmed from the torsion angles $\mathrm{C} 2-\mathrm{N} 3-\mathrm{C} 19-\mathrm{C} 20=46.5^{\circ}$ and $\mathrm{C} 2-\mathrm{N} 3-\mathrm{C} 19-\mathrm{C} 24=-136.6^{\circ}$ and the other phenyl group on $\mathrm{N} 1$ shows a rather small dihedral angle $\mathrm{C} 2-\mathrm{N} 1-\mathrm{C} 8-\mathrm{C} 9=0.9^{\circ}$.

Table 1. Structural parameters of diphenylguanidine determined by B3LYP method with 6-31G**, 6-311++G** and cc-pVDZ basis sets

\begin{tabular}{ccccc}
\hline $\begin{array}{c}\text { Structural } \\
\text { Parameters }\end{array}$ & $\begin{array}{c}\text { B3LYP/ } \\
\text { 6-31G** }\end{array}$ & $\begin{array}{c}\text { B3LYP/ } \\
\text { 6-311++G** }\end{array}$ & $\begin{array}{c}\text { B3LYP/ } \\
\text { cc-pVDZ }\end{array}$ & Expt. $^{a}$ \\
\hline $\begin{array}{c}\text { Internuclear distance }(\AA) \\
\text { N1-C2 }\end{array}$ & 1.39 & 1.39 & 1.38 & 1.37 \\
N1-H5 & 1.01 & 1.01 & 1.01 & 0.86 \\
N1-C8 & 1.41 & 1.41 & 1.40 & 1.40 \\
C2-N3 & 1.42 & 1.42 & 1.41 & 1.40 \\
C2-N4 & 1.28 & 1.28 & 1.27 & 1.28 \\
N3-H6 & 1.01 & 1.01 & 1.01 & 0.86 \\
N3-C19 & 1.41 & 1.41 & 1.40 & 1.42 \\
N4-H7 & 1.02 & 1.02 & 1.01 & 0.86 \\
C8-C9 & 1.40 & 1.40 & 1.40 & 1.39 \\
C8-C13 & 1.41 & 1.40 & 1.40 & 1.38 \\
C9-C10 & 1.40 & 1.39 & 1.39 & 1.36 \\
C9-H14 & 1.08 & 1.08 & 1.08 & 0.93 \\
C10-C11 & 1.39 & 1.39 & 1.39 & 1.36 \\
C10-H15 & 1.09 & 1.08 & 1.08 & 0.93 \\
C11-C12 & 1.40 & 1.39 & 1.39 & 1.37 \\
C11-H16 & 1.09 & 1.08 & 1.08 & 0.93 \\
C12-C13 & 1.39 & 1.39 & 1.39 & 1.39 \\
C12-H17 & 1.09 & 1.08 & 1.08 & 0.93 \\
C13-H18 & 1.09 & 1.09 & 1.08 & 0.93 \\
C19-C20 & 1.40 & 1.40 & 1.40 & 1.35 \\
C19-C24 & 1.40 & 1.40 & 1.40 & 1.34 \\
\hline & & & & Condt...
\end{tabular}




\begin{tabular}{ccccc}
\hline C20-C21 & 1.39 & 1.39 & 1.39 & 1.39 \\
C20-H25 & 1.08 & 1.08 & 1.08 & 0.93 \\
C21-C22 & 1.40 & 1.39 & 1.39 & 1.32 \\
C21-H26 & 1.09 & 1.08 & 1.08 & 0.93 \\
C22-C23 & 1.40 & 1.39 & 1.39 & 1.30 \\
C22-H27 & 1.09 & 1.08 & 1.08 & 0.93 \\
C23-C24 & 1.39 & 1.39 & 1.39 & 1.37 \\
C23-H28 & 1.09 & 1.08 & 1.08 & 0.93 \\
C24-H29 & 1.09 & 1.09 & 1.08 & 0.93 \\
Bond angle (') & & & & \\
C2-N1-H5 & 114.4 & 114.6 & 114.5 & 115.0 \\
C2-N1-C8 & 130.0 & 130.1 & 130.3 & 130.0 \\
H5-N1-C8 & 114.8 & 114.9 & 114.7 & 115.0 \\
N1-C2-N3 & 109.3 & 109.5 & 109.4 & 112.9 \\
N1-C2-N4 & 123.1 & 123.2 & 123.3 & 122.4 \\
N3-C2-N4 & 127.6 & 127.2 & 127.3 & 124.7 \\
C2-N3-H6 & 113.8 & 113.9 & 113.9 & \\
C2-N3-C19 & 124.8 & 124.3 & 125.2 & 118.3 \\
H6-N3-C19 & 114.3 & 114.2 & 114.2 & 115.0 \\
C2-N4-H7 & 110.4 & 111.1 & 111.2 & 120.0 \\
N1-C8-C9 & 124.0 & 124.0 & 124.1 & 124.5 \\
N1-C8-C13 & 116.8 & 116.8 & 116.8 & 117.2 \\
C9-C8-C13 & 119.2 & 119.1 & 119.1 & 118.3 \\
C8-C9-C10 & 119.4 & 119.4 & 119.5 & 120.4 \\
C9-C10-C11 & 121.5 & 121.5 & 121.5 & 121.3 \\
C10-C11-C12 & 119.0 & 119.0 & 119.0 & 119.2 \\
C11-C12-C13 & 120.3 & 120.3 & 120.3 & 120.4 \\
C8-C13-C12 & 120.6 & 120.7 & 120.8 & 120.2 \\
N3-C19-C20 & 121.6 & 121.3 & 121.8 & 122.0 \\
N3-C19-C24 & 119.3 & 119.5 & 119.2 & 121.9 \\
C20-C19-C24 & 119.1 & 119.1 & 118.9 & 115.8 \\
C19-C20-C21 & 119.9 & 120.0 & 120.0 & 121.8 \\
C20-C21-C22 & 120.9 & 120.8 & 120.9 & 120.8 \\
C21-C22-C23 & 119.2 & 119.2 & 119.1 & 117.9 \\
C22-C23-C24 & 120.5 & 120.4 & 120.4 & 122.5 \\
C19-C24-C23 & 120.5 & 120.5 & 120.6 & 121.2 \\
\hline & & & \\
& & & & \\
\hline
\end{tabular}

${ }^{a}$ values are taken from Ref. [29]

\section{Analysis of molecular electrostatic potential}

The hydrogen bonding, reactivity and structure-activity relationship of biomolecules and drugs can be discussed by molecular electrostatic potential (MEP) ${ }^{30}$. The electrophilic or nucleophilic reactive sites and the path along which the reactant molecules approach each other are found by electrostatic potential. The shape, size, charge density distribution and the sites of chemical reactivity of a molecule can be predicted with electron density surface mapped with electrostatic potential. The total electron density mapped electrostatic potential surface of DPG is presented in Figure 2(b). Local negative electrostatic potentials (red) reside on nitrogen which corresponds to the most nucleophilic regions, whereas local positive electrostatic potentials (blue) lie on hydrogen in N-H group which represents the 
most electrophilic regions. Among the nitrogen atoms N4 possess more negative potential than others. Green areas cover parts of the molecule where electrostatic potentials are close to zero (C-C bonds). The MEP of the molecule lie in the range $+1.224 \mathrm{e} \times 10^{-2}$ to $-1.224 \mathrm{e} \times 10^{-2}$. The total electron density of DPG lie in the range $+5.545 \mathrm{e} \times 10^{-2}$ to $-5.545 \mathrm{e} \times 10^{-2}$. The MEP and total electron density shows that the DPG is more polar and reactive.

\section{Analysis of frontier molecular orbitals}

The energies of HOMO, LUMO, LUMO+1 and HOMO-1 and the LUMO-HOMO energy gap are calculated by using B3LYP/6-311++G** method. The charge transfer interface within the molecule is revealed by the LUMO-HOMO energy gap. The hardness and softness of the molecule depends on the frontier molecular orbital energies. The LUMO-HOMO energy gap of DPG is $5.1117 \mathrm{eV}$. The molecular orbital energies and global reactivity properties of DPG determined by B3LYP/6-311++G** method are summarised in Table 2.

Table 2. The calculated molecular orbital energies and global reactivity properties of diphenylguanidine by B3LYP/6-311++G** method

\begin{tabular}{cccccc}
\hline $\begin{array}{c}\mathrm{E}_{\mathrm{LUMO}+1} \\
(\mathrm{eV})\end{array}$ & $\mathrm{E}_{\mathrm{LUMO}}(\mathrm{eV})$ & $\mathrm{E}_{\mathrm{HOMO}}(\mathrm{eV})$ & $\begin{array}{c}\mathrm{E}_{\mathrm{HOMO}-1} \\
(\mathrm{eV})\end{array}$ & $\begin{array}{c}\mathrm{E}_{\mathrm{LUMO}}- \\
\mathrm{E}_{\mathrm{HOMO}}(\mathrm{eV})\end{array}$ & $\begin{array}{c}\text { Ionisation } \\
\text { potential, } \mathrm{I}(\mathrm{eV})\end{array}$ \\
\hline-0.7494 & -0.8248 & -5.9365 & -6.3034 & 5.1117 & 7.7358 \\
$\begin{array}{c}\text { Electron } \\
\text { Elfinity, } \mathrm{A}(\mathrm{eV})\end{array}$ & $\begin{array}{c}\text { Electro } \\
\text { negativity }(\chi)\end{array}$ & $\begin{array}{c}\text { Chemical } \\
\text { potential }(\mu)\end{array}$ & $\begin{array}{c}\text { Electrophili } \\
\text { city }(\omega)\end{array}$ & Hardness $(\eta)$ & Softness $(\mathrm{S})$ \\
-0.2102 & 3.7628 & -3.7628 & 1.7819 & 3.9730 & 0.1259 \\
\hline
\end{tabular}

The essence of FMO theory is that the highest occupied molecular orbital (HOMO) and lowest unoccupied molecular orbital (LUMO) suffice to describe the reactivity of a molecule ${ }^{31}$. In this case one has to obtain

$$
f^{+}(r)=\left|\psi^{\text {HOMO }}(r)\right|^{2} \text { and } f^{-}(r)=\left|\psi^{\text {LUMO }}(r)\right|^{2}
$$

The distribution of the electrophilic sites in a system can be derived from the theory of frontier molecular orbitals ${ }^{32}$ within the frozen core approximation ${ }^{33}$. The sites where the HOMO frontier orbital attains its larger absolute value are analysed to find out the distribution of electrophilic sites. The energy of the HOMO is directly related to the ionization potential and chracterises the susceptibility of the molecule towards attack by electrophiles. A large HOMO-LUMO gap implies high stability for the molecule in the sense of its lower reactivity in chemical reactions ${ }^{34}$. The qualitative definition of hardness is closely related to the polarizability, since a decrease of the energy gap usually leads to easier polarization of the molecule $\mathrm{e}^{35}$.

\section{Natural bond orbital (NBO) analysis}

The information regarding atomic charge, Lewis structure, bond type, hybridisation, bond order, charge transfer and resonance possibilities can be determined by analyzing the natural bonding orbitals. The type of bond orbitals, their occupancies, the natural atomic hybrids of which the NBO is composed, giving the percentage of the NBO on each hybrid, the atom label and a hybrid label showing the hybrid orbital $\left(\mathrm{sp}^{\mathrm{x}}\right)$ composition (the amount of $s$-character, $p$-character, etc.) of DPG are investigated. All bonding donor orbitals have two electrons. The bonding orbital for $\mathrm{C} 2-\mathrm{N} 4$ has $36.53 \% \mathrm{C} 2$ character and has $63.47 \% \mathrm{~N} 4$ character in a hybrid orbital. This bond has $100 \% p$-character shows the presence of double bond. The bonding orbital for N1-C2 has $62.07 \% \mathrm{~N} 1$ character in a $\mathrm{sp}^{1.73}$ hybrid and has 
$37.93 \% \mathrm{C} 2$ character in a $\mathrm{sp}^{2.32}$ hybrid orbital. The bonding orbital for $\mathrm{C} 2-\mathrm{N} 3$ has $38.07 \% \mathrm{C} 2$ character in a $\mathrm{sp}^{2.24}$ hybrid and has $61.93 \% \mathrm{~N} 3$ character in a $\mathrm{sp}^{1.94}$ hybrid orbital. This clearly reveals the partial double bond character of N1-C2 and $\mathrm{C} 2-\mathrm{N} 3$ bonds. The bonding orbital for N1-C8 with 1.9866 electrons has $62.08 \% \mathrm{~N} 1$ character and $37.92 \% \mathrm{C} 8$ character. The bonding orbital for N3-C19 has $61.35 \%$ N3 character and $38.65 \%$ C19 character. The $\mathrm{C}-\mathrm{C}$ bonds of the benzene ring possess more $p$ character than $s$ character. This clearly indicates the elocalization of $\pi$ electrons among all the carbon atoms of the phenyl ring.

The donor-acceptor interactions and their elocalizatio energies of DPG using NBO analysis is presented in Table 3 . The bond pair donor orbital, $\pi_{\mathrm{CC}} \rightarrow \pi^{*}{ }_{\mathrm{CC}}$ interaction between the phenyl ring carbon atoms are more elocaliza and the elocalizatio energy of these interactions lie in the range $16.97-22.78 \mathrm{kcal} \mathrm{mol}^{-1}$. The lone pair donor orbital, $\mathrm{n}_{\mathrm{N}} \rightarrow$ $\pi^{*}{ }_{\mathrm{CN}}$ interaction between the nitrogen (N1) lone pair and the $\mathrm{C} 2=\mathrm{N} 4$ antibonding orbital gives very strong elocalizatio by $48.14 \mathrm{kcal} \mathrm{mol}^{-1}$ while the lone pair donor orbital, $\mathrm{n}_{\mathrm{N}} \rightarrow$ $\pi^{*}{ }_{\mathrm{CC}}$ interaction between the nitrogen (N1) lone pair and the $\mathrm{C} 8=\mathrm{C} 9$ antibonding orbital gives strong elocalizatio by $33.23 \mathrm{kcal} \mathrm{mol}^{-1}$.

Table 3. Second order perturbation theory analysis of diphenylguanidine by B3LYP/6$311++\mathrm{G}^{* *}$ method using NBO analysis

\begin{tabular}{cccc}
\hline $\begin{array}{c}\text { Donor(i) }- \text { Acceptor }(\mathrm{j}) \\
\text { interaction }\end{array}$ & $\begin{array}{c}\mathrm{E}^{(2) \mathrm{a}}, \\
\mathrm{kcal} \mathrm{mol}^{-1}\end{array}$ & $\begin{array}{c}\mathrm{E}(\mathrm{j})-\mathrm{E}(\mathrm{i})^{\mathrm{b}} \\
(\text { a.u. }\end{array}$ & $\begin{array}{c}\mathrm{F}(\mathrm{i}, \mathrm{j})^{\mathrm{e}} \\
(\text { a.u. })\end{array}$ \\
\hline$\sigma(\mathrm{N} 4-\mathrm{H} 7) \rightarrow \sigma^{*}(\mathrm{~N} 1-\mathrm{C} 2)$ & 11.31 & 1.03 & 0.097 \\
$\pi(\mathrm{C} 8=\mathrm{C} 9) \rightarrow \pi^{*}(\mathrm{C} 10=\mathrm{C} 11)$ & 22.24 & 0.29 & 0.072 \\
$\pi(\mathrm{C} 8=\mathrm{C} 9) \rightarrow \pi^{*}(\mathrm{C} 12=\mathrm{C} 13)$ & 18.71 & 0.28 & 0.065 \\
$\pi(\mathrm{C} 10=\mathrm{C} 11) \rightarrow \pi^{*}(\mathrm{C} 8=\mathrm{C} 9)$ & 18.64 & 0.28 & 0.065 \\
$\pi(\mathrm{C} 10=\mathrm{C} 11) \rightarrow \pi^{*}(\mathrm{C} 12=\mathrm{C} 13)$ & 22.78 & 0.28 & 0.071 \\
$\pi(\mathrm{C} 12=\mathrm{C} 13) \rightarrow \pi^{*}(\mathrm{C} 8=\mathrm{C} 9)$ & 20.32 & 0.29 & 0.07 \\
$\pi(\mathrm{C} 12=\mathrm{C} 13) \rightarrow \pi^{*}(\mathrm{C} 10=\mathrm{C} 11)$ & 16.97 & 0.29 & 0.064 \\
$\pi(\mathrm{C} 19=\mathrm{C} 24) \rightarrow \pi^{*}(\mathrm{C} 20=\mathrm{C} 21)$ & 17.79 & 0.29 & 0.064 \\
$\pi(\mathrm{C} 19=\mathrm{C} 24) \rightarrow \pi^{*}(\mathrm{C} 22=\mathrm{C} 23)$ & 22.11 & 0.29 & 0.072 \\
$\pi(\mathrm{C} 20=\mathrm{C} 21) \rightarrow \pi^{*}(\mathrm{C} 19=\mathrm{C} 24)$ & 22.17 & 0.28 & 0.071 \\
$\pi(\mathrm{C} 20=\mathrm{C} 21) \rightarrow \pi^{*}(\mathrm{C} 22=\mathrm{C} 23)$ & 18.02 & 0.29 & 0.065 \\
$\pi(\mathrm{C} 22=\mathrm{C} 23) \rightarrow \pi^{*}(\mathrm{C} 19=\mathrm{C} 24)$ & 19.22 & 0.27 & 0.066 \\
$\pi(\mathrm{C} 22=\mathrm{C} 23) \rightarrow \pi^{*}(\mathrm{C} 20=\mathrm{C} 21)$ & 22.50 & 0.28 & 0.071 \\
$\mathrm{n}(\mathrm{N} 1) \rightarrow \pi^{*}(\mathrm{C} 2=\mathrm{N} 4)$ & 48.14 & 0.29 & 0.106 \\
$\mathrm{n}(\mathrm{N} 1) \rightarrow \pi^{*}(\mathrm{C} 8=\mathrm{C} 9)$ & 33.23 & 0.31 & 0.092 \\
$\mathrm{n}(\mathrm{N} 3) \rightarrow \pi^{*}(\mathrm{C} 2=\mathrm{C} 4)$ & 28.41 & 0.31 & 0.085 \\
$\mathrm{n}(\mathrm{N} 3) \rightarrow \pi^{*}(\mathrm{C} 19=\mathrm{C} 24)$ & 24.78 & 0.31 & 0.081 \\
$\mathrm{n}(\mathrm{N} 4) \rightarrow \sigma^{*}(\mathrm{C} 2-\mathrm{N} 3)$ & 16.90 & 0.77 & 0.102 \\
\hline
\end{tabular}

${ }^{a}$ Stabilisation ( elocalization) energy. ${ }^{b}$ Energy difference between $i$ (donor) and $j$ (acceptor) NBO orbitals. ${ }^{e}$ Fock matrix element $i$ and $j \mathrm{NBO}$ orbitals

\section{Analysis of structure - reactivity descriptors \\ Topological charge distribution analysis}

In DPG, the Mullikan atomic charges, natural atomic charges, electrostatic potential derived atomic charges, Hirshfeld atomic charges, Chelpg charges of atoms are calculated by B3LYP/6-311++G** method and presented in Table 4. The electrostatic interactions namely inter- and intramolecular interactions depend on the atomic charges of a compound. The chemical information obtained from charge density analysis enables us to know how the 
structure can exist, how the compound exhibits chemical and biological reactivity and where the interaction sites/regions localize. In DPG, the nitrogen (N4) has more negative charge when compared to N1 and N3. This reveals the possibility of the electrophilic attack at N4 on sulphurisation process. The carbon atom $\mathrm{C} 2$ possesses positive charge except Mullikan method and this suggests that nucleophilic attack predominate at this carbon atom.

The charge distribution in DPG provides better understanding of chemical reactivity and clearly favours the sulphurisation process and that is why DPG is considered the best vulcanization accelerator. The $\mathrm{C} 8$ and $\mathrm{C} 19$ have positive charges due to the electronic effect of nitrogen atoms. All other carbon possesses negative charges. The calculated $\sigma-$ and $\pi$ electron densities on a particular atom also characterize the possible orientation of the chemical interactions and thus, are often considered to be directional reactivity indices. In contrast, overall electron densities and net charges on atoms are considered as nondirectional reactivity indices ${ }^{36}$.

Table 4. Atomic charges of diphenylguanidine using B3LYP/6-311++G** method

\begin{tabular}{cccccc}
\hline Atom & MULLIKAN & NBO & ESP & HIRSHFELD & CHELPG \\
\hline N1 & -0.0978 & -0.6081 & -0.7216 & -0.0848 & -0.7905 \\
C2 & -0.3026 & 0.6126 & 0.8639 & 0.1540 & 0.9176 \\
N3 & 0.0248 & -0.6492 & -0.8322 & -0.1049 & -0.8290 \\
N4 & -0.3920 & -0.7431 & -0.8090 & -0.2672 & -0.7597 \\
H5 & 0.3042 & 0.3842 & 0.3646 & 0.1195 & 0.3702 \\
H6 & 0.2380 & 0.3832 & 0.3603 & 0.1197 & 0.3587 \\
H7 & 0.2361 & 0.3474 & 0.3162 & 0.0837 & 0.2657 \\
C8 & -0.1051 & 0.1666 & 0.5216 & 0.0461 & 0.4951 \\
C9 & 0.6751 & -0.2376 & -0.2956 & -0.0589 & -0.2353 \\
C10 & -0.1734 & -0.1807 & -0.0522 & -0.0393 & -0.0338 \\
C11 & -0.3161 & -0.2309 & -0.2575 & -0.0572 & -0.1820 \\
C12 & -0.2518 & -0.1906 & -0.0079 & -0.0453 & 0.0035 \\
C13 & -0.6404 & -0.2377 & -0.4115 & -0.0675 & -0.3274 \\
H14 & 0.2555 & 0.2506 & 0.1702 & 0.0278 & 0.1220 \\
H15 & 0.1742 & 0.2026 & 0.1199 & 0.0430 & 0.0846 \\
H16 & 0.1417 & 0.2031 & 0.1416 & 0.0391 & 0.0939 \\
H17 & 0.1691 & 0.2028 & 0.1138 & 0.0418 & 0.0743 \\
H18 & 0.1142 & 0.1938 & 0.1621 & 0.0349 & 0.1233 \\
C19 & -0.3473 & 0.1584 & 0.4925 & 0.0428 & 0.4304 \\
C20 & 0.2340 & -0.2431 & -0.2598 & -0.0550 & -0.1990 \\
C21 & -0.1522 & -0.1814 & -0.1226 & -0.0370 & -0.0823 \\
C22 & -0.3972 & -0.2244 & -0.1713 & -0.0516 & -0.1080 \\
C23 & -0.1837 & -0.1838 & -0.1017 & -0.0393 & -0.0626 \\
C24 & -0.0313 & -0.2335 & -0.3223 & -0.0617 & -0.2453 \\
H25 & 0.1908 & 0.2199 & 0.1723 & 0.0440 & 0.1324 \\
H26 & 0.1815 & 0.2063 & 0.1350 & 0.0461 & 0.0936 \\
H27 & 0.1461 & 0.2064 & 0.1350 & 0.0426 & 0.0840 \\
H28 & 0.1767 & 0.2057 & 0.1361 & 0.0451 & 0.0908 \\
H29 & 0.1289 & 0.2004 & 0.1600 & 0.0392 & 0.1150 \\
\hline & & & & & \\
\hline
\end{tabular}

Dipole moment and polarity indices

The atomic charges and dipole moment of the molecule describes the polarity of a molecule. The total dipole moment reflects only the global polarity of a molecule. The total dipole 
moment of DPG is determined by B3LYP/6-311++G** method is $2.9010 \mathrm{D}$ shows that the polar nature of DPG molecule. The molecular dipole moment features the possible intermolecular interactions as descriptors in structure-activity relations.

\section{Fukui reactivity descriptors}

The structural and quantum chemical descriptors provide meaningful information of the compounds. The constitutional, topological, geometrical and electrostatic descriptors are structural descriptors. The electronic and quantum chemical descriptors are extensively applied to probe the local reactivity and site selectivity. The formal definitions of all these Fukui descriptors and working equations for their computation have been described ${ }^{37,38}$. The Fukui reactivity descriptors $\left(f_{k}\right)$ of the individual atoms of DPG are calculated by B3LYP/6-311++G** method. In the present study, both local reactivity and multiphilicity descriptors are used to probe the nature of attack/reactivity at a particular site in the molecule. The Fukui dual reactivity descriptor $\left(\Delta \mathrm{f}_{\mathrm{k}}\right)$, the dual local softness $\left(\Delta \mathrm{s}_{\mathrm{k}}\right)$ and the multiphilicity descriptors $\left(\Delta \omega_{\mathrm{k}}\right)$ which can concurrently haracterizes both nucleophilic and electrophilic nature of a chemical species.

The Fukui dual descriptors; $\Delta \mathrm{f}_{\mathrm{k}}$ (Table 5), the dual local softness; $\Delta \mathrm{s}_{\mathrm{k}}$ (Table 6) and the multiphilicity descriptors; $\Delta \omega_{\mathrm{k}}$ (Table 7 ) have also been determined to predict the reactive sites of the DPG molecule. The relative thermodynamic and kinetic stabilities are discussed through the hardness and softness of the molecule. The hardness of DPG determined by B3LYP/6 $-311++\mathrm{G}^{* *}$ method is 3.9730 while the softness is 0.1259 .

In the present investigation the atoms C2, C13, C22 and C24 are most prone to nucleophilic attack while the electrophilic attack is more on $\mathrm{C} 2, \mathrm{C} 19$ and $\mathrm{C} 12$ atoms. The sites C2, C12, C19, C22 and C24 are more susceptible to free radical attack.

If $\Delta \mathrm{f}_{\mathrm{k}}, \Delta \mathrm{s}_{\mathrm{k}}$ and $\Delta \omega_{\mathrm{k}}$ are greater than zero, then the site $k$ is favoured for a nucleophilic attack, whereas if these are less than zero, then the site $k$ may be favored for an electrophilic attack. From $\Delta \mathrm{f}_{\mathrm{k}}, \Delta \mathrm{s}_{\mathrm{k}}$ and $\Delta \omega_{\mathrm{k}}$ values one can understand that the atoms $\mathrm{C} 2, \mathrm{C} 9, \mathrm{C} 21$ and $\mathrm{C} 22$ are more favorable for nucleophilic attack. The atoms N1, N3, C8, C19 and C23 are more favorable for electrophilic attack.

Table 5. The Fukui dual reactivity descriptors $\left(\Delta f_{\mathrm{k}}\right)$ of diphenylguanidine by B3LYP/6$311++\mathrm{G}^{* *}$ method

\begin{tabular}{lrrrrr}
\hline Atom & MULLIKAN & NBO & ESP & HIRSHFELD & CHELPG \\
\hline N1 & -0.0246 & 0.8185 & 0.3469 & 0.0613 & 0.6385 \\
C2 & 1.1926 & -0.6179 & 0.1477 & 0.0050 & -0.1467 \\
N3 & -0.0048 & 0.6578 & 0.4231 & 0.0362 & 0.5597 \\
N4 & 0.1125 & 0.8823 & -0.1792 & 0.0146 & -0.0582 \\
C8 & 0.3486 & -0.0735 & -0.1226 & 0.0429 & -0.3038 \\
C9 & 0.4664 & 0.3168 & -0.0296 & 0.0395 & 0.0923 \\
C10 & -0.4101 & 0.1947 & 0.0780 & 0.0237 & -0.0207 \\
C11 & 0.5962 & 0.3967 & 0.1892 & 0.0668 & 0.2712 \\
C12 & 0.6340 & 0.2032 & 0.0061 & 0.0269 & -0.0577 \\
C13 & -0.4619 & 0.3266 & 0.3773 & 0.0371 & 0.4915 \\
C19 & 0.7974 & -0.1673 & -0.2981 & 0.0122 & -0.2815 \\
C20 & 0.5268 & 0.2546 & -0.0811 & 0.0110 & -0.0046 \\
C21 & -0.8989 & 0.1867 & 0.0132 & 0.0088 & 0.0525 \\
C22 & 0.9998 & 0.2369 & 0.3231 & 0.0330 & 0.2284 \\
C23 & 0.6318 & 0.2010 & -0.1154 & 0.0085 & -0.0481 \\
C24 & -0.8136 & 0.2511 & 0.4818 & 0.0147 & 0.4661 \\
\hline
\end{tabular}


Table 6. The dual local softness descriptors $\left(\Delta s_{k}\right)$ of phenylguanidine by B3LYP/6$311++\mathrm{G}^{* *}$ method

\begin{tabular}{cccccc}
\hline Atom & MULLIKAN & NBO & ESP & HIRSHFELD & CHELPG \\
\hline N1 & -0.0031 & 0.1031 & 0.0437 & 0.0077 & 0.0804 \\
C2 & 0.1502 & -0.0778 & 0.0186 & 0.0006 & -0.0185 \\
N3 & -0.0006 & 0.0828 & 0.0533 & 0.0046 & 0.0705 \\
N4 & 0.0142 & 0.1111 & -0.0226 & 0.0018 & -0.0073 \\
C8 & 0.0439 & -0.0093 & -0.0154 & 0.0054 & -0.0383 \\
C9 & 0.0587 & 0.0399 & -0.0037 & 0.0050 & 0.0116 \\
C10 & -0.0516 & 0.0245 & 0.0098 & 0.0030 & -0.0026 \\
C11 & 0.0751 & 0.0499 & 0.0238 & 0.0084 & 0.0341 \\
C12 & 0.0798 & 0.0256 & 0.0008 & 0.0034 & -0.0073 \\
C13 & -0.0582 & 0.0411 & 0.0475 & 0.0047 & 0.0619 \\
C19 & 0.1004 & -0.0211 & -0.0375 & 0.0015 & -0.0354 \\
C20 & 0.0663 & 0.0320 & -0.0102 & 0.0014 & -0.0006 \\
C21 & -0.1132 & 0.0235 & 0.0017 & 0.0011 & 0.0066 \\
C22 & 0.1259 & 0.0298 & 0.0407 & 0.0041 & 0.0288 \\
C23 & 0.0795 & 0.0253 & -0.0145 & 0.0011 & -0.0061 \\
C24 & -0.1024 & 0.0316 & 0.0607 & 0.0019 & 0.0587 \\
\hline
\end{tabular}

Table 7. The multiphilicity descriptors $\left(\Delta \omega_{\mathrm{k}}\right)$ of diphenylguanidine by B3LYP/6-311++G** method

\begin{tabular}{cccccc}
\hline Atom & MULLIKAN & NBO & ESP & HIRSHFELD & CHELPG \\
\hline N1 & -0.0439 & 1.4585 & 0.6182 & 0.1092 & 1.1377 \\
C2 & 2.1251 & -1.1010 & 0.2633 & 0.0089 & -0.2613 \\
N3 & -0.0085 & 1.1722 & 0.7539 & 0.0644 & 0.9973 \\
N4 & 0.2005 & 1.5721 & -0.3193 & 0.0261 & -0.1037 \\
C8 & 0.6211 & -0.1310 & -0.2184 & 0.0764 & -0.5414 \\
C9 & 0.8310 & 0.5645 & -0.0527 & 0.0704 & 0.1644 \\
C10 & -0.7307 & 0.3469 & 0.1389 & 0.0423 & -0.0368 \\
C11 & 1.0624 & 0.7069 & 0.3372 & 0.1190 & 0.4832 \\
C12 & 1.1297 & 0.3621 & 0.0109 & 0.0479 & -0.1029 \\
C13 & -0.8231 & 0.5820 & 0.6722 & 0.0661 & 0.8758 \\
C19 & 1.4208 & -0.2981 & -0.5311 & 0.0217 & -0.5016 \\
C20 & 0.9386 & 0.4536 & -0.1445 & 0.0196 & -0.0083 \\
C21 & -1.6017 & 0.3327 & 0.0236 & 0.0156 & 0.0935 \\
C22 & 1.7816 & 0.4220 & 0.5757 & 0.0587 & 0.4069 \\
C23 & 1.1257 & 0.3581 & -0.2057 & 0.0151 & -0.0857 \\
C24 & -1.4497 & 0.4475 & 0.8586 & 0.0263 & 0.8305 \\
\hline
\end{tabular}

\section{Molecular polarizability and hyperpolarizability analysis}

The ability of the molecule to participate in van der Waals and dispersion interactions depends on polarizability and is also related to hydrophobicity and other biological activities ${ }^{39,40}$. The first hyperpolarizability of DPG computed by B3LYP/6-311++G** method are presented in the Table 8 . The first-order polarizability tensor contains information about possible inductive interactions in the DPG molecule. The non-linear optical activity of the molecular system depends on hyperpolarizability $(\beta)$ and is associated with the intramolecular charge transfer, resulting from the electron cloud movement through $\pi$ conjugated 
frame work from electron donor to electron acceptor groups. Molecules with high hyperpolarizability have chromophores, since the compound DPG is a conjugative system with $\mathrm{N}-\mathrm{H}$ chromophore and hence its hyperpolarizability values determined is in the order of more than $10 \times 10^{-24}$ e.s.u. The asymmetric molecule DPG has large values of molecular hyperpolarisability, $\beta$ due to the electron tabilized es along a conjugated backbone. The total anisotropy of the polarizability (second-order term) tabilized es the electron acceptor properties of DPG molecule ${ }^{41,42}$.

Table 8. Dipole moment, average polarizability, first polarizability and hyperpolarisability tensors of diphenyl guanidine determined by B3LYP/6-311++G(d,p) method

\begin{tabular}{cccccc}
\hline$\mu_{\text {total }}(\mathrm{D})$ & 2.9010 & $\alpha_{\text {total }}$ (e.s.u) & $82.5228 \times 10^{-24}$ & $\beta_{\mathrm{yzz}}$ & 2.1947 \\
\hline$\alpha_{\mathrm{xx}}$ & 279.698 & $\Delta \alpha($ a.u $)$ & 146.6811 & $\beta_{\mathrm{zzz}}$ & -22.8895 \\
$\alpha_{\mathrm{xy}}$ & 4.4968 & $\beta_{\mathrm{xxx}}$ & 523.196 & $\beta_{\mathrm{x}}$ & 520.3099 \\
$\alpha_{\mathrm{yy}}$ & 159.55 & $\beta_{\mathrm{xxy}}$ & 360.113 & $\beta_{\mathrm{x}}{ }^{2}$ & $27.0722 \times 10^{4}$ \\
$\alpha_{\mathrm{xz}}$ & -4.2710 & $\beta_{\mathrm{xyy}}$ & 19.8626 & $\beta_{\mathrm{y}}$ & 282.4212 \\
$\alpha_{\mathrm{yz}}$ & 0.5559 & $\beta_{\mathrm{yyy}}$ & -79.8865 & $\beta_{\mathrm{y}}{ }^{2}$ & $79.7617 \times 10^{3}$ \\
$\alpha_{\mathrm{zz}}$ & 116.804 & $\beta_{\mathrm{xxz}}$ & -81.4424 & $\beta_{\mathrm{z}}$ & -99.9822 \\
$\alpha_{0}$ (a.u) & 185.3507 & $\beta_{\mathrm{xyz}}$ & -44.0633 & $\beta_{\mathrm{z}}{ }^{2}$ & $99.9644 \times 10^{2}$ \\
$\alpha_{0}$ (e.s.u) & $27.4690 \times 10{ }^{24}$ & $\beta_{\mathrm{yyz}}$ & 4.3497 & $\beta_{0}$ (a.u) & $36.0480 \times 10^{4}$ \\
$\alpha_{\text {total }}$ (a.u) & 556.8337 & $\beta_{\mathrm{xzz}}$ & -22.7487 & $\beta_{0}$ (e.s.u) & $5.3423 \times 10{ }^{28}$ \\
\hline
\end{tabular}

\section{Conclusion}

1. The structure and the reactivity of diphenylguanidine focusing on the properties of aromatic substituted guanidine moiety have been discussed by DFT methods.

2. Studies show that the imino form of diphenylguanidine is more favoured structure and is confirmed by DFT investigations.

3. The bond distance of N1-C2 and N3-C2 are $1.39 \AA$ and $1.42 \AA$, respectively. Thus, the N1-C2 bonds always possess much more double-bond character than the C2-N3 with the longer $\mathrm{C}-\mathrm{N}$ bond length, though both have partial double-bond character. The C-N bond which connects the phenyl ring has bond length of in the range 1.28-1.30 $\AA$ typical to $\mathrm{C}=\mathrm{N}$ double bond (ca. $1.28 \AA$ ) and is shorter than the other two $\mathrm{C}-\mathrm{N}$ bonds of the tabilize group.

4. The tabilize group is planar and is confirmed by bond angles and torsion angles. The N1-C2-N3 bond angle $\left(109.5^{\circ}\right)$ is always smaller than the other two (N1-C2-N4 $\left(123.2^{\circ}\right)$ and $\left.\mathrm{N} 3-\mathrm{C} 2-\mathrm{N} 4\left(127.2^{\circ}\right)\right)$.

5. The MEP of the molecule lie in the range $+1.224 \mathrm{e} \times 10^{-2}$ to $-1.224 \mathrm{e} \times 10^{-2}$. The total electron density of DPG spreads between $+5.545 \mathrm{e} \times 10^{-2}$ and $-5.545 \mathrm{e} \times 10^{-2}$.

6. The bonding orbital for $\mathrm{C} 2-\mathrm{N} 3$ has $38.07 \% \mathrm{C} 2$ character in a $\mathrm{sp}^{2.24}$ hybrid and has $61.93 \% \mathrm{~N} 3$ character in a $\mathrm{sp}^{1.94}$ hybrid orbital. This clearly reveals that the partial double bond character of N1-C2 and $\mathrm{C} 2-\mathrm{N} 3$ bonds.

7. The bond pair donor orbital, $\pi_{\mathrm{CC}} \rightarrow \pi^{*}{ }_{\mathrm{CC}}$ interaction between the phenyl ring carbon atoms are more tabilized and the stabilization energy of these interactions lie in the range $16.97-22.78 \mathrm{kcal} \mathrm{mol}^{-1}$.

8. The large total dipole moment of DPG $(2.901 \mathrm{D})$ shows that the polar nature of DPG molecule.

9. The atoms $\mathrm{C} 2, \mathrm{C} 13, \mathrm{C} 22$ and $\mathrm{C} 24$ are most prone to nucleophilic attack while the electrophilic attack is more on $\mathrm{C} 2, \mathrm{C} 19$ and $\mathrm{C} 12$ atoms. The sites C2, C10, C12, C13, C19, C21, C22 and C24 are more susceptible to free radical attack. 
10. Fukui dual reactivity descriptor $\left(\Delta \mathrm{f}_{\mathrm{k}}\right)$, the dual local softness $\left(\Delta \mathrm{s}_{\mathrm{k}}\right)$ and the multiphilicity descriptors $\left(\Delta \omega_{\mathrm{k}}\right)$ reveals that the atoms $\mathrm{C} 2, \mathrm{C} 9, \mathrm{C} 21$ and $\mathrm{C} 22$ are more favorable for nucleophilic attack. The atoms N1, N3, C8, C19 and C23 are more favorable for electrophilic attack.

\section{Acknowledgment}

This research work is not getting any support from the institutions and not getting fund from any funding agency.

\section{References}

1. Sullivan A B, Hann C J and Kuhls G H, Rubber Chem Technol., 1992, 65(2), 488501; DOI: $10.5254 / 1.3538626$

2. Kresja M R and Koenig J L, Rubber Chem Technol., 1993, 66(3), 376-410; DOI:10.5254/1.3538317

3. Gradwell M H S and McGill W J, J Appl Polym Sci., 1995, 58(12), 2193-2200; DOI:10.1002/app.1995.070581206

4. http://www.hnxnchem.com/product/ra/guanidines/

5. https://www.arkema.com/

6. Chamakjian H H, J Chem Educ., 1931, 8, 2060; DOI:10.1021/ed008p2060

7. https://www.credenceresearch.com/

8. Camarasa J M and Alomar A, Contact Derm., 1978, 4(4), 242-244.

9. Calnan C D, Contact Derm., 1978, 4(3), 168-169; DOI:10.1111/j.16000536.1978.tb03769.x

10. Saha M, Srinivas S and Shenoy D, Contact Derm., 1993, 28, 260-264.

11. Scherz M W, Fialeix M, Fischer J B, Reddy N L, Server A C, Sonders M S, Tester B C, Weber E, Wong S T and Keana J F W, J Med Chem., 1990, 33(9), 2421-2429; DOI:10.1021/jm00171a016

12. Bhoumick S and Banerjee S, Rubber Chem Tech., 1974, 47(2), 251-265; DOI:10.5254/1.3540435

13. Frisch M J, Trucks G W, Schlegel H B, Scuseria G E, Robb M A, Cheeseman J R, Scalmani G, Barone V, Mennucci B, Petersson G A, Nakatsuji H, Caricato M, Li X, Hratchian H P, Izmaylov A F, Bloino J, Zheng G, Sonnenberg J L, Hada M, Ehara M, Toyota K, Fukuda R, Hasegawa J, Ishida M, Nakajima T, Honda Y, Kitao O, Nakai H, Vreven T, Montgomery J A, Peralta Jr J E, Ogliaro F, Bearpark M, Heyd J J, Brothers E, Kudin K N, Staroverov V N, Kobayashi R, Normand J, Raghavachari K, Rendell A, Burant J C, Iyengar S S, Tomasi J, Cossi M, Rega N, Millam J M, Klene M, Knox J E, Cross J B, Bakken V, Adamo C, Jaramillo J, Gomperts R, Stratmann R E, Yazyev O, Austin A J, Cammi R, Pomelli C, Ochterski J W, Martin R L, Morokuma K, Zakrzewski V G, Voth G A, Salvador P, Dannenberg J J, Dapprich S, Daniels A D, Farkas O, Foresman J B, Ortiz J V, Cioslowski J and Fox D J, Gaussian 09, Revision A.02, Gaussian, Inc., Wallingford CT, 2009.

14. Schlegel H B, J Comput Chem., 1982, 3(2), 214-218; DOI:10.1002/jcc.540030212

15. Hohenberg P and Kohn W, Phys Rev., 1964, B136, 864-871;

DOI:10.1103/PhysRev.136.B864

16. Becke A D, J Chem Phys., 1993, 98, 5648-5652; DOI:10.1063/1.464913

19. Becke A D, Phys Rev., 1988, A38, 3098-3100; DOI:10.1103/PhysRevA.38.30987

18. Lee C, Yang W and Parr R G, Phys Rev., 1988, B 37(2), 785-789;

DOI:10.1103/PhysRevB.37.785 
19. Murray J S and Sen K, Molecular Electrostatic Potentials, Concepts and Applications, Elsevier, Amsterdam, 1996.

20. Dennington R I, Keith T and Millam J, GaussView, Version 5.0.8, Semichem. Inc. Shawnee Mission, KS, 2008.

21. Reed A E and Weinhold F, J Chem Phys., 1985, 83, 1736-1740; DOI:10.1063/1.449360

22. Reed A E, Weinstock R B and Weinhold F, J Chem Phys., 1985, 83, 735-746; DOI:10.1063/1.449486

23. Reed A E and Weinhold F, J Chem Phys., 1983, 78, 4066-4073; DOI:10.1063/1.445134

24. Foster J P and Weinhold F, J Am Chem Soc., 1980, 102, 7211-7218; DOI:10.1021/ja00544a007

25. Parr R G and Yang W, J Am Chem Soc., 1984, 106(4), 4049-4050; DOI:10.1021/ja00326a036

26. Yang W and Parr R G, Proc Natl Acad Sci USA. 1985, 82, 6723-6726; DOI:10.1073/pnas.82.20.6723

27. Tanatani A, Yamaguchi K, Azumaya I, Fukutomi R, Shudo K and Kagechika H, J Am Chem Soc., 1998, 120(26), 6433-6442; DOI:10.1021/ja9806534

28. Binoy J, James C, Hubert Joe I and Jayakumar V S, J Mol Struct., 2006, 784(1-3), $32-$ 46; DOI:10.1016/j.molstruc.2005.06.038

29. Paixao J A, Beja A M, Silva P S P, Silva M R, da Veiga L A, CCDC 131383: Experimental Crystal Structure Determination, 1999, DOI:10.5517/cc4dq5d

30. Chidangil C, Shukla M K and Mishra P C, Mol Model Annual, 1998, 4(8), 250-258; DOI: $10.1007 / \mathrm{s} 008940050082$

31. Bultinck P, Fias S, Van Alsenoy C, Ayers P W and Carbó-Dorca R, J Chem Phys., 2007, 127, 034102; DOI:10.1063/1.2749518

32. Fukui K, Yonezawa $\mathrm{T}$ and Shingu H, J Chem Phys., 1952, 20, 722-725; DOI:10.1063/1.1700523

33. Parr R G and Yang W, Density Functional Theory of Atoms and Molecules, Oxford University Press, New York, 1989.

34. Lewis D F V, Ioannides C and Parke D V, Xenobiotica, 1994, 24(5), 401-408; DOI: $10.3109 / 00498259409043243$

35. Pearson R G, J Org Chem., 1989, 54(6), 1423-1430; DOI:10.1021/jo00267a034

36. Scriven E F V and Ramsden C A, (Eds.), Advances in Heterocyclic Chemistry. Heterocyclic Chemistry in the $21^{\text {st }}$ Century: A Tribute to Alan Katritzky, Elsevier, Amsterdam, 2016, 249.

37. Geerlings P, De Proft F and Langenaeker W, Chem Rev., 2003, 103(5), 1793-1873; DOI:10.1021/cr990029p

38. Pearson R G, Chemical Hardness-Applications from Molecules to Solids, VCH Wiley, Weinheim, 1997.

39. Cammarata A, J Med Chem., 1967, 10(4), 525-527; DOI:10.1021/jm00316a004

40. Leo A, Hansch C and Church C, J Med Chem., 1969, 12(5), 766-771; DOI:10.1021/jm00305a010

41. Lewis D F V, J Comput Chem., 1987, 8(8), 1084-1089; DOI:10.1002/jcc.540080803

42. Grunenberg J and Herges R, J Chem Inf Comput Sci., 1995, 35(5), 905-911; DOI:10.1021/ci00027a018 